\title{
Overall natural radioactivity of a phosphate fertilizer industry in Korea
}

\author{
M.H. Song ${ }^{1}$, B.U. Chang ${ }^{1,2}$, S.M. Koh ${ }^{3}$, Y.J. Kim ${ }^{1,2}$, D.J. Kim ${ }^{1}$ and G.H. Kim ${ }^{2}$ \\ ${ }^{1}$ Korea Institute of Nuclear Safety, 34 Gwahak-ro, Yuseong-gu, 305-338 \\ Daejeon, Republic of Korea \\ ${ }^{2}$ University of Science and Technology, 113 Gwahak-ro, Yuseong-gu, 305-333 \\ Daejeon, Republic of Korea \\ ${ }^{3}$ Korea Institute of Geoscience and Mineral Resources, 92 Gwahak-ro, Yuseong-gu, 305-350 \\ Daejeon, Republic of Korea
}

\begin{abstract}
The phosphogypsum is produced as a by-product of the manufacturing phosphoric acid or phosphate fertilizer from the phosphate rock on the wet process. In general, it contains relatively high concentrations of uranium series radionuclides such as ${ }^{226} \mathrm{Ra}$. This study surveyed overall radioactivity of the naturally occurring radionuclides in a facility using phosphate rock and evaluated the impact on the vicinity environment by the phosphogypsum.
\end{abstract}

\section{INTRODUCTION}

The phosphate rock (PR) is well known as Naturally Occurring Radioactive Material (NORM). The $\mathrm{PR}$ is used as a raw material to produce the phosphoric acid (PA) using for production of the phosphate fertilizer (PF). The phosphogypsum (PG) generated as a by-product in these manufacturing process is well known as Technically Enhanced Naturally Occurring Radioactive Material (TENORM). Typically, ${ }^{226} \mathrm{Ra}(80 \%),{ }^{232} \mathrm{Th}(30 \%)$ and ${ }^{238} \mathrm{U}(14 \%)$ are remained in the PG and the rest of the natural radionuclides are transferred in the PA [3]. With this reason, occasionally a waste contaminated with high level of ${ }^{226} \mathrm{Ra}$ activity has been discovered. In Korea, scrap irons contaminated with the NORM scales have been discovered since 1998 where most of them had been imported from foreign country with lack of identification of its origin. Three of discovered thirty five cases were identified that the scrap irons originated from the PF industry.

Namhae Chemical Co. is the biggest facility in Korea using PR that is imported from China, Jordan, Morocco and Togo [1]. The imported PR is used to produce the PA that was produced approximately 0.2 million tons in 2009. The company produced approximately 0.8 million tons of PF with the produced PA. In these manufacturing processes, approximately 1 million tons of the PG was generated as a byproduct. In addition, the scale attached on the inside of the components was also generated where the quantity was approximately 10 tons. Some of the PG are recycled by manufacturers producing the gypsum board, and the remainders including the scale are piled up at the open storage yard (PG stack). The PG may cause the radiation exposure to the workers and have an adverse impact on the surrounding environment.

This study evaluated the overall natural radioactivity in the PF industry and the surface dose-rate on the components in the manufacturing process. In addition, environmental impact from the natural radionuclides in the PG was estimated. 


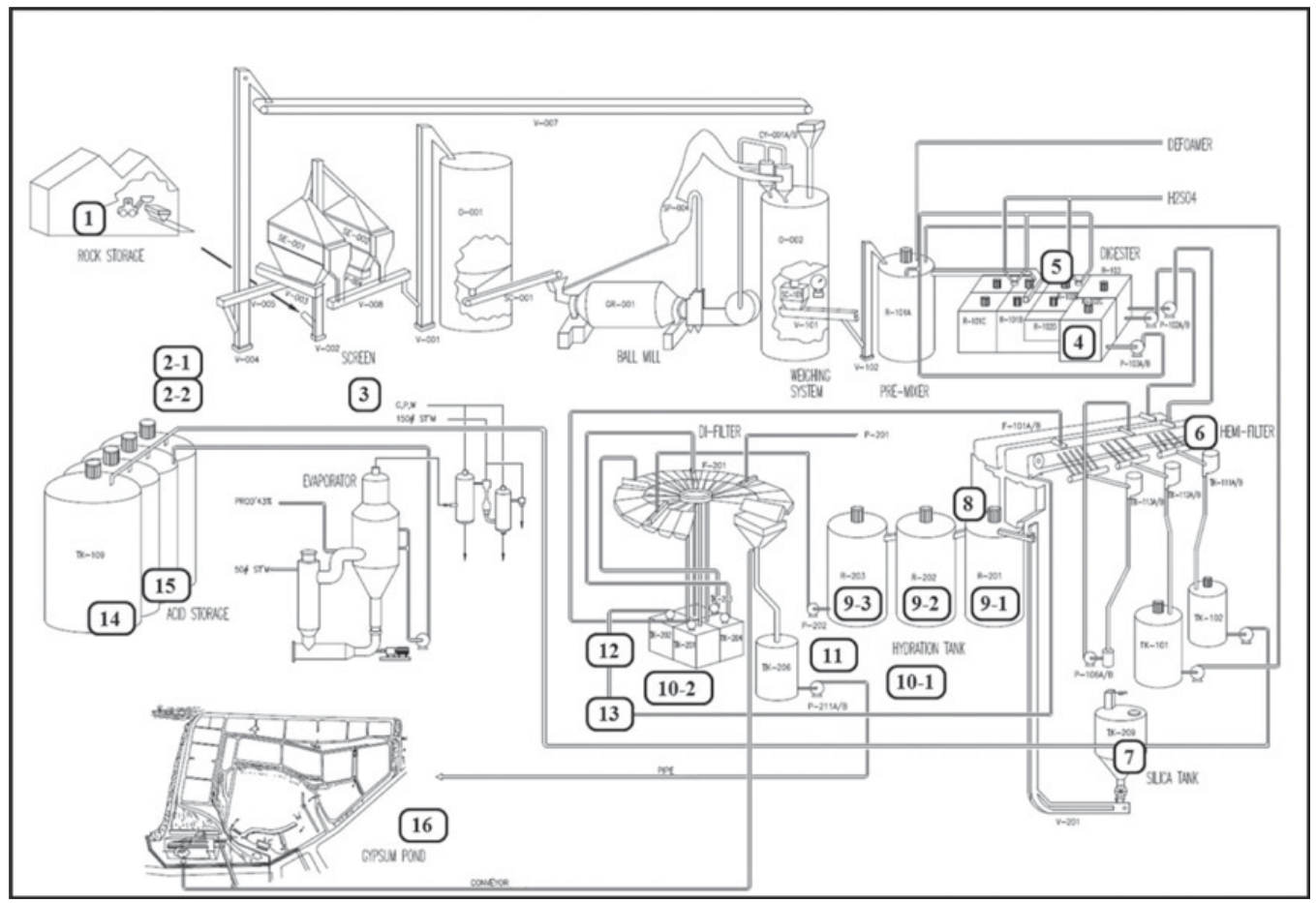

* The numbers are the measurement points of surface dose-rate.

Figure 1. Measurement points of surface dose-rate.

\section{MATERIAL AND METHOD}

The activities of the natural radionuclides such as ${ }^{226} \mathrm{Ra},{ }^{232} \mathrm{Th}$ and ${ }^{40} \mathrm{~K}$ in the PR, PG, scale, PA and $\mathrm{PF}$ were analyzed by the gamma-ray spectrometry using a p-type HPGe detector with 30 percentage of relative efficiency. The system was calibrated using a commercial mixed gamma source $\left({ }^{214} \mathrm{Am},{ }^{109} \mathrm{Cd}\right.$, ${ }^{57} \mathrm{Co},{ }^{203} \mathrm{Hg},{ }^{113} \mathrm{Sn},{ }^{85} \mathrm{Sr},{ }^{137} \mathrm{Cs},{ }^{88} \mathrm{Y}$ and $\left.{ }^{60} \mathrm{Co}\right)$ certified by Eckert \& Ziegler. The ${ }^{226} \mathrm{Ra}$ concentrations were determined by measuring the activities of its decay product ${ }^{214} \mathrm{Bi}(609 \mathrm{keV}$ peak) that were in secular equilibrium with ${ }^{226} \mathrm{Ra}$ following the 25 days storage. The ${ }^{232} \mathrm{Th}$ concentrations were determined by measuring the activities of its decay product ${ }^{228} \mathrm{Ac}\left(911 \mathrm{keV}\right.$ peak). The ${ }^{40} \mathrm{~K}$ concentrations were directly determined through its $1460 \mathrm{keV}$ peak.

The surface dose-rate of components, scale, scrap iron, and etc. were measured by the high sensitivity personal radiation dosimeter (RadEye PRD, Thermo Scientific) using a NaI detector. Figure 1 shows the diagram on the manufacturing process.

The soil samples were collected from 40 points $(10 \mathrm{~cm}$ and $30 \mathrm{~cm}$ in depth from surface, respectively) with regular grid in distance to establish the environmental impact by the stacked PG (Figure 2) [2]. The activities of the natural radionuclides such as ${ }^{226} \mathrm{Ra},{ }^{232} \mathrm{Th}$ and ${ }^{40} \mathrm{~K}$ in soils were analyzed by the gamma-ray spectrometry.

\section{RESULTS AND DISCUSSION}

\section{1 ${ }^{226} \mathrm{Ra},{ }^{232} \mathrm{Th}$ and ${ }^{40} \mathrm{~K}$ activities in the materials}

The ranges of the ${ }^{226} \mathrm{Ra},{ }^{232} \mathrm{Th}$ and ${ }^{40} \mathrm{~K}$ activities in the PR, PG, scale, PA and PF are summarized in Table 1 . The ${ }^{226} \mathrm{Ra}$ and ${ }^{232} \mathrm{Th}$ activities in the PR, PG and PF samples were lower than the typical 


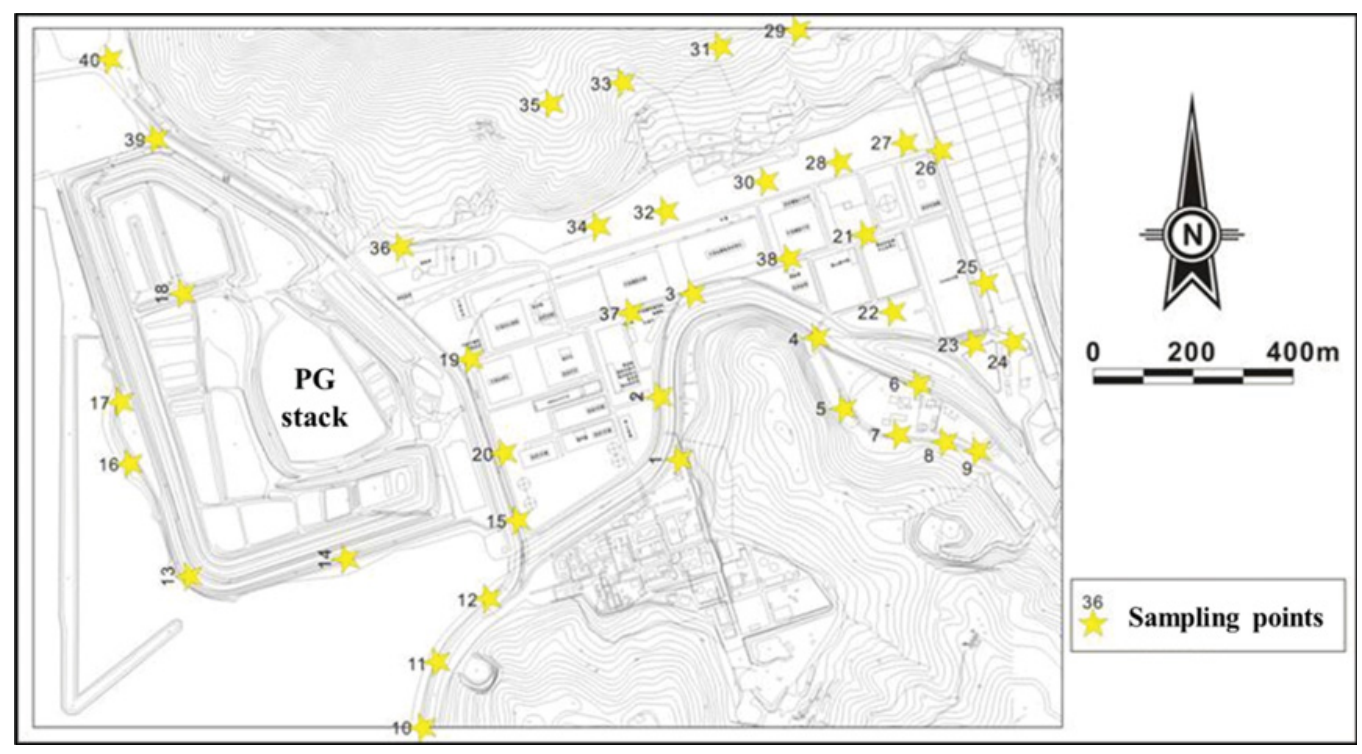

Figure 2. Sampling locations of the soil samples [2].

Table 1. The ranges of the ${ }^{226} \mathrm{Ra},{ }^{232} \mathrm{Th}$ and ${ }^{40} \mathrm{~K}$ activities in the PR, scale, PA, PG, and PF samples.

\begin{tabular}{|c|c|c|c|c|}
\hline \multirow{2}{*}{ Sample } & \multirow{2}{*}{$\begin{array}{c}\text { Number } \\
\text { of samples }\end{array}$} & \multicolumn{3}{|c|}{ Activity $\left(\mathrm{Bq} \cdot \mathrm{kg}^{-1}\right)$} \\
\cline { 3 - 5 } & 5 & ${ }^{226}$ Ra (average) & ${ }^{232}$ Th (average) & ${ }^{40} \mathrm{~K}$ (average) \\
\hline Phosphate Rock (China) & 1 & $12,210 \pm 697$ & $150 \pm 12$ & $<5.7-69.5(44.5)$ \\
\hline Scale & 2 & $*$ & $6.0-35.0(20.5)$ & Not Detectable \\
\hline Phosphoric Acid & 8 & $432-844(618)$ & $4.6-11.3(8.5)$ & $8.6-37.9(24.1)$ \\
\hline Phosphogypsum & 2 & $100-510(305)$ & $3.0-7.0(5.0)$ & $20.0-80.0(50.0)$ \\
\hline Phosphate Fertilizer & & &
\end{tabular}

* The range of the ${ }^{238} \mathrm{U}$ activities in the PA samples analyzed by ICP Mass was $800-1,400 \mathrm{~Bq} \cdot \mathrm{kg}^{-1}$.

concentrations of the natural radionuclides in the phosphate industry given in the UNSCEAR report [4]. However the ${ }^{226} \mathrm{Ra}$ activity in the scale sample was significantly high where the scale samples were taken from the inside of the pipeline transporting the PG to the PG stack.

\subsection{Surface dose-rate at the manufacturing process}

The ranges of the surface dose-rate on the components, raw material and PG sludge are summarized in Table 2. Most of the measured surface dose-rates were similar to the typical outdoor gamma dose-rate in Korea $\left(0.05-0.30 \mu \mathrm{Sv} \cdot \mathrm{h}^{-1}\right)$. However, the surface dose-rates on the pipelines, particularly at the joint of the pipelines, were significantly high compared to the others, because the scale adhered to the inside of the pipeline. Therefore, it is recommended to protect the descaling workers against the radiation exposure.

\section{$3.3{ }^{226} \mathrm{Ra},{ }^{232} \mathrm{Th}$ and ${ }^{40} \mathrm{~K}$ activities in soils}

The ranges of ${ }^{226} \mathrm{Ra},{ }^{232} \mathrm{Th}$ and ${ }^{40} \mathrm{~K}$ activities in the soil samples at $10 \mathrm{~cm}$ in depth from surface were 15.6-704 Bq. kg ${ }^{-1}, 19.0-72.7 \mathrm{~Bq} \cdot \mathrm{kg}^{-1}$ and $191-1,136 \mathrm{~Bq} \cdot \mathrm{kg}^{-1}$, respectively. In the soil samples at 30 
Table 2. The surface dose-rate at the manufacturing process.

\begin{tabular}{|l|c|c|c|}
\hline $\begin{array}{l}\text { Measured points } \\
\text { (the number in Figure 1) }\end{array}$ & $\begin{array}{c}\text { Surface dose-rate } \\
\left(\mu \mathrm{Sv} \cdot \mathrm{h}^{-1}\right)\end{array}$ & $\begin{array}{c}\text { Measured points } \\
\text { (the number in Figure 1) }\end{array}$ & $\begin{array}{c}\text { Surface dose-rate } \\
\left(\mu \mathrm{Sv} \cdot \mathrm{h}^{-1}\right)\end{array}$ \\
\hline Phosphate Rock storage (1) & $0.07-0.08$ & Hydration tank (9-2) & $0.18-0.20$ \\
\hline Inside scraped T-joint (2-1) & $4.20-8.50$ & Hydration tank (9-3) & $1.50-1.80$ \\
\hline Outside scraped T-joint (2-2) & $3.50-4.00$ & Passage (10-1) & $0.3-0.7$ \\
\hline Hard scale in pipeline (3) & $0.37-0.47$ & Passage (10-2) & $0.3-0.4$ \\
\hline Digester (4) & $0.32-0.50$ & $\begin{array}{c}\text { Aisle of around } \\
\text { hydration tank (11) }\end{array}$ & $1.85-2.50$ \\
\hline Scruba of digester (5) & $0.07-0.08$ & Pipeline (12) & $1.50-2.00$ \\
\hline Hemi-filter (6) & $0.09-0.25$ & L-joint (13) & 3.06 \\
\hline Silica tank (7) & $0.50-0.67$ & Acid storage tank (14) & $0.41-0.53$ \\
\hline Scruba of hydration tank (8) & $0.56-0.60$ & Acid storage tank (15) & $0.18-0.21$ \\
\hline Hydration tank (9-1) & $0.30-0.40$ & $\begin{array}{c}\text { Temporary stored } \\
\text { sludge (16) }\end{array}$ & $0.55-0.64$ \\
\hline
\end{tabular}
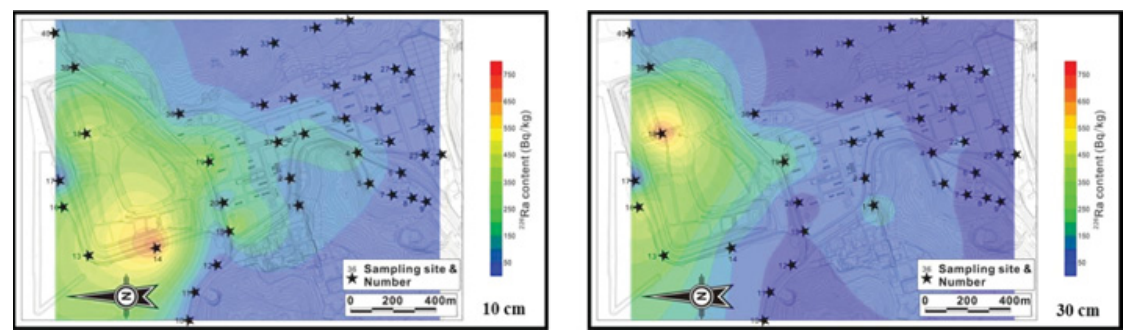

Figure 3. Distribution of the ${ }^{226} \mathrm{Ra}$ activities in the soil samples at $10 \mathrm{~cm}$ and $30 \mathrm{~cm}$ in depth from surface [2].

$\mathrm{cm}$ in depth from surface, the ranges of ${ }^{226} \mathrm{Ra},{ }^{232} \mathrm{Th}$ and ${ }^{40} \mathrm{~K}$ activities were $17.3-710 \mathrm{~Bq} \cdot \mathrm{kg}^{-1}, 17.4$ $62.9 \mathrm{~Bq} \cdot \mathrm{kg}^{-1}$ and $193-1,166 \mathrm{~Bq} \cdot \mathrm{kg}^{-1}$, respectively (Table 3). Most of the ${ }^{226} \mathrm{Ra}$ activities in the soils were lower than those of the PG. However, ${ }^{226} \mathrm{Ra}$ activities in the soils near the PG stack were high and similar to those of the PG. In addition, the ${ }^{226} \mathrm{Ra}$ activities in the several locations far from the PG stack also indicated the high concentration (Figure 3). This is caused by the stacked PG at the open storage yard. The stacked PG might be transferred to the surrounding soils by wind and the transported PG might be washed into the deep soil layer by precipitation suggesting deposition of ${ }^{226} \mathrm{Ra}$ into the soils. The activities of ${ }^{232} \mathrm{Th}$ and ${ }^{40} \mathrm{~K}$ in soils were low in the vicinity of PG stack and they were also lower than those of PG. This was estimated to originate from the geological characteristic of the region (Figure 4 and 5). In the case of ${ }^{40} \mathrm{~K}$, the original characteristics of the surrounding geology containing potash feldspar and the illite rich rocks were reflected [2].

\section{CONCLUSION}

The activities of the natural radionuclides and the surface dose-rate in the manufacturing process of PA and PF were generally not significant level. However, ${ }^{226} \mathrm{Ra}$ was highly concentrated in the NORM scale, PG attached to the inside of the pipeline, and it has been confirmed that the workers handling the scale may be exposed to high radiation dose. ${ }^{226} \mathrm{Ra}$ activities in soils at some parts of the site were high caused by the stacked PG. In particular, ${ }^{226}$ Ra activities near the PG stack were high and it found no significant difference between soils at $10 \mathrm{~cm}$ and $30 \mathrm{~cm}$ in depths from surface. 
Table 3. The ${ }^{226} \mathrm{Ra},{ }^{232} \mathrm{Th}$ and ${ }^{40} \mathrm{~K}$ activities in the soil at $10 \mathrm{~cm}$ and $30 \mathrm{~cm}$ in depth from the surface.

\begin{tabular}{|c|c|c|c|c|c|c|}
\hline \multirow{3}{*}{ ID } & \multicolumn{6}{|c|}{ Activity $\left(\mathrm{Bq} \cdot \mathrm{kg}^{-1}\right)$} \\
\hline & \multicolumn{2}{|c|}{${ }^{226} \mathrm{Ra}$} & \multicolumn{2}{|c|}{${ }^{232} \mathrm{Th}$} & \multicolumn{2}{|c|}{${ }^{40} \mathrm{~K}$} \\
\hline & $10 \mathrm{~cm}$ & $30 \mathrm{~cm}$ & $10 \mathrm{~cm}$ & $30 \mathrm{~cm}$ & $10 \mathrm{~cm}$ & $30 \mathrm{~cm}$ \\
\hline 1 & $77 \pm 1$ & $124 \pm 1$ & $46 \pm 1$ & $44 \pm 1$ & $809 \pm 11$ & $659 \pm 11$ \\
\hline 2 & $71 \pm 1$ & $46 \pm 2$ & $42 \pm 1$ & $28 \pm 1$ & $770 \pm 11$ & $742 \pm 18$ \\
\hline 3 & $145 \pm 3$ & $73 \pm 2$ & $37 \pm 1$ & $41 \pm 3$ & $679 \pm 19$ & $704 \pm 17$ \\
\hline 4 & $125 \pm 2$ & $43 \pm 1$ & $42 \pm 2$ & $40 \pm 3$ & $724 \pm 14$ & $846 \pm 17$ \\
\hline 5 & $69 \pm 2$ & $77 \pm 1$ & $53 \pm 2$ & $54 \pm 1$ & $771 \pm 17$ & $780 \pm 11$ \\
\hline 6 & $38 \pm 2$ & $36 \pm 1$ & $48 \pm 1$ & $46 \pm 2$ & $735 \pm 18$ & $720 \pm 14$ \\
\hline 7 & $29 \pm 1$ & $28 \pm 1$ & $41 \pm 3$ & $46 \pm 1$ & $825 \pm 12$ & $850 \pm 11$ \\
\hline 8 & $47 \pm 2$ & $39 \pm 1$ & $42 \pm 4$ & $54 \pm 1$ & $812 \pm 12$ & $917 \pm 13$ \\
\hline 9 & $30 \pm 1$ & $31 \pm 1$ & $48 \pm 3$ & $43 \pm 1$ & $934 \pm 19$ & $895 \pm 19$ \\
\hline 10 & $38 \pm 2$ & $46 \pm 1$ & $46 \pm 1$ & $47 \pm 2$ & $595 \pm 16$ & $616 \pm 11$ \\
\hline 11 & $42 \pm 1$ & $43 \pm 2$ & $34 \pm 1$ & $41 \pm 2$ & $799 \pm 14$ & $862 \pm 11$ \\
\hline 12 & $29 \pm 1$ & $35 \pm 2$ & $30 \pm 1$ & $37 \pm 1$ & $754 \pm 19$ & $782 \pm 19$ \\
\hline 13 & $411 \pm 3$ & $58 \pm 1$ & $21 \pm 1$ & $42 \pm 1$ & $297 \pm 7$ & $724 \pm 15$ \\
\hline 14 & $704 \pm 5$ & $103 \pm 1$ & $19 \pm 4$ & $38 \pm 1$ & $191 \pm 7$ & $586 \pm 10$ \\
\hline 15 & $27 \pm 1$ & $49 \pm 1$ & $37 \pm 1$ & $22 \pm 1$ & $917 \pm 16$ & $675 \pm 16$ \\
\hline 16 & $320 \pm 3$ & $441 \pm 3$ & $33 \pm 1$ & $20 \pm 3$ & $519 \pm 17$ & $255 \pm 13$ \\
\hline 17 & $23 \pm 1$ & $27 \pm 1$ & $35 \pm 3$ & $44 \pm 1$ & $955 \pm 17$ & $1,166 \pm 12$ \\
\hline 18 & $447 \pm 5$ & $710 \pm 8$ & $30 \pm 2$ & $23 \pm 2$ & $455 \pm 9$ & $229 \pm 15$ \\
\hline 19 & $339 \pm 3$ & $205 \pm 2$ & $25 \pm 5$ & $37 \pm 1$ & $312 \pm 9$ & $553 \pm 10$ \\
\hline 20 & $84 \pm 2$ & $21 \pm 1$ & $20 \pm 1$ & $17 \pm 1$ & $546 \pm 14$ & $548 \pm 8$ \\
\hline 21 & $16 \pm 1$ & $23 \pm 1$ & $19 \pm 1$ & $37 \pm 1$ & $655 \pm 13$ & $740 \pm 16$ \\
\hline 22 & $36 \pm 1$ & $56 \pm 1$ & $73 \pm 2$ & $62 \pm 2$ & $1,136 \pm 13$ & $969 \pm 13$ \\
\hline 23 & $23 \pm 1$ & $22 \pm 1$ & $40 \pm 1$ & $37 \pm 1$ & $689 \pm 16$ & $697 \pm 11$ \\
\hline 24 & $24 \pm 1$ & $25 \pm 1$ & $38 \pm 1$ & $39 \pm 1$ & $687 \pm 17$ & $669 \pm 14$ \\
\hline 25 & $25 \pm 1$ & $17 \pm 1$ & $30 \pm 2$ & $37 \pm 3$ & $651 \pm 24$ & $532 \pm 10$ \\
\hline 26 & $37 \pm 2$ & $56 \pm 1$ & $40 \pm 1$ & $44 \pm 1$ & $719 \pm 18$ & $784 \pm 18$ \\
\hline 27 & $29 \pm 2$ & $29 \pm 1$ & $49 \pm 4$ & $53 \pm 2$ & $442 \pm 12$ & $448 \pm 11$ \\
\hline 28 & $34 \pm 1$ & $31 \pm 2$ & $58 \pm 3$ & $61 \pm 4$ & $411 \pm 14$ & $193 \pm 13$ \\
\hline & & & & & & continue \\
\hline 29 & $26 \pm 1$ & $28 \pm 2$ & $40 \pm 2$ & $44 \pm 4$ & $356 \pm 12$ & $361 \pm 18$ \\
\hline 30 & $35 \pm 1$ & $36 \pm 1$ & $51 \pm 4$ & $63 \pm 2$ & $540 \pm 21$ & $571 \pm 17$ \\
\hline 31 & $29 \pm 1$ & $35 \pm 1$ & $52 \pm 4$ & $60 \pm 5$ & $454 \pm 18$ & $506 \pm 13$ \\
\hline 32 & $37 \pm 1$ & $41 \pm 1$ & $57 \pm 2$ & $62 \pm 2$ & $490 \pm 11$ & $519 \pm 10$ \\
\hline 33 & $30 \pm 1$ & $31 \pm 2$ & $45 \pm 2$ & $45 \pm 4$ & $499 \pm 19$ & $489 \pm 18$ \\
\hline 34 & $30 \pm 1$ & $34 \pm 2$ & $47 \pm 1$ & $49 \pm 1$ & $677 \pm 18$ & $699 \pm 19$ \\
\hline 35 & $32 \pm 2$ & $28 \pm 2$ & $37 \pm 4$ & $37 \pm 3$ & $530 \pm 19$ & $543 \pm 17$ \\
\hline 36 & $63 \pm 1$ & $49 \pm 1$ & $57 \pm 5$ & $56 \pm 2$ & $595 \pm 21$ & $652 \pm 13$ \\
\hline 37 & $104 \pm 1$ & $80 \pm 1$ & $41 \pm 2$ & $44 \pm 2$ & $622 \pm 20$ & $679 \pm 13$ \\
\hline 38 & $41 \pm 1$ & - & $30 \pm 1$ & - & $716 \pm 10$ & - \\
\hline 39 & $135 \pm 1$ & $122 \pm 1$ & $24 \pm 1$ & $27 \pm 1$ & $609 \pm 15$ & $658 \pm 10$ \\
\hline 40 & $102 \pm 1$ & $96 \pm 1$ & $37 \pm 1$ & $33 \pm 3$ & $833 \pm 11$ & $794 \pm 11$ \\
\hline
\end{tabular}



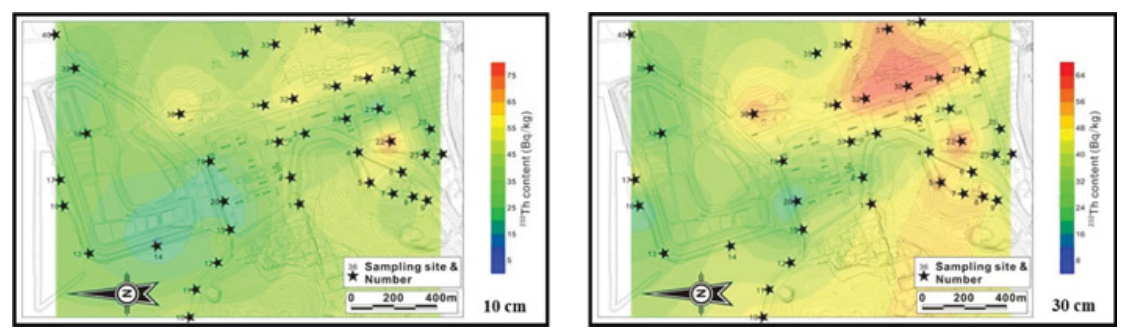

Figure 4. Distribution of the ${ }^{232} \mathrm{Th}$ activities in the soil samples at $10 \mathrm{~cm}$ and $30 \mathrm{~cm}$ in depth from surface [2].
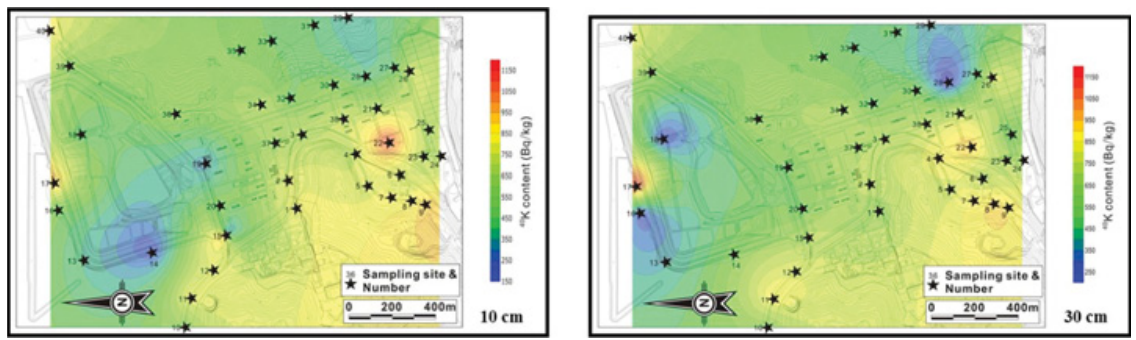

Figure 5. Distribution of the ${ }^{40} \mathrm{~K}$ activities in the soil samples at $10 \mathrm{~cm}$ and $30 \mathrm{~cm}$ in depth from surface [2].

Recently, Namhae Chemical Co. makes an effort to manage the natural radiation in the manufacturing process of PA and PF. The company regularly measures the radiation dose and the generated scrap irons are discarded after descaling the NORM scale and measuring the radiation dose.

There are many facilities using the raw materials containing the naturally occurring radionuclides in Korea. However, manufacturers and workers related with NORM/TENORM industry are still not aware of the radiation exposure. Furthermore, although the lead, bismuth and polonium radioisotopes, the decay products of radon, are heavy-weight in radiation exposure of the workers by the natural radionuclides, their studies have not yet been carried out in Korea. Therefore, more varying aspects of researches for the natural radiation in the facilities need to be conducted and under management of the Government. Recently, Korean Government (MEST) is making an effort to establish the regulatory framework for the natural radiation.

\section{Acknowledgments}

This study was supported by the Nuclear Technology R\&D program of the Ministry of Education, Science and Technology (MEST) in Korea.

\section{References}

[1] Chang B. U., Kim Y. J., and Oh J. J., Radiat. Prot. Dosimetry, (2011), 10.1093/rpd/ncr140

[2] Korean Institute of Nuclear Safety, Investigation on the natural radioactive industrial materials, (2010), in Korean

[3] United Nations Scientific Committee on the Effects of Atomic Radiation, Sources and effects of ionizing radiation. UNSCEAR 1993 Report to the General Assembly with Scientific Annexes, (1993)

[4] United Nations Scientific Committee on the Effects of Atomic Radiation, Exposures from natural radiation sources. UNSCEAR 2000 Report to the General Assembly with Scientific Annexes, (2000) 